indicated by the movement of the galvanometer needle. A thin strip of hard rubber, placed in the instrument, exhibits extreme sensitiveness, being expanded by heat from the hand, so as to move through several degrees the needle of a very ordinary galvanometer, which is not affected in the slightest degree by a thermopile facing and near a red-hot iron. The hand, in this experiment, is held a few inches from the rubber strip. A strip of mica is sensibly affected by the heat of the hand, and a strip of gelatin, placed in the instrument, is instantly expanded by moisture from a dampened piece of paper held two or three inches away.

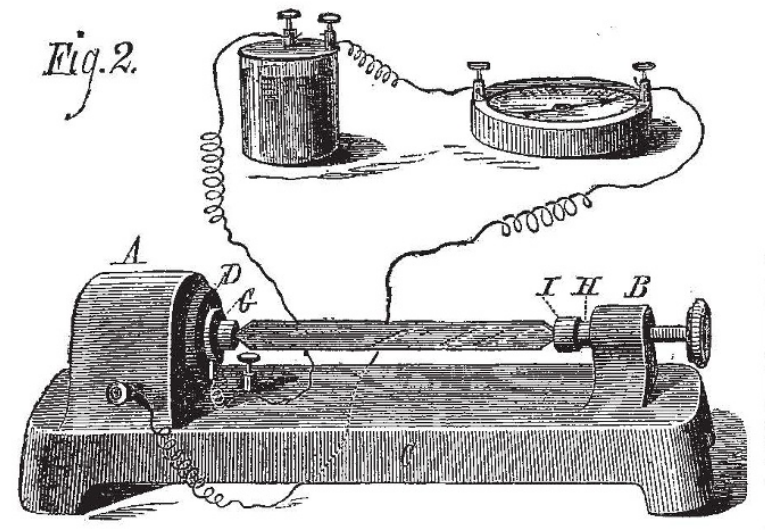

For these experiments the instrument is arranged as in Fig. 2, but for more delicate operations it is connected with a Thomson's reflecting galvanometer, and the current is regulated by a Wheatstone's bridge and a rheostat, so that the resistance on both sides of the galvanometer is equal, and the light-pencil from the reflector falls on $0^{\circ}$ of the scale. This arrangement is shown in Fig. I, and the principle is illustrated by the diagram, Fig. 4. Here the galvanometer is at $g$, and the instrument which is at $i$ is adjusted, say, for example, to ten ohms resistance. At $a, b$, and $c$ the resistance is the same. An increase or

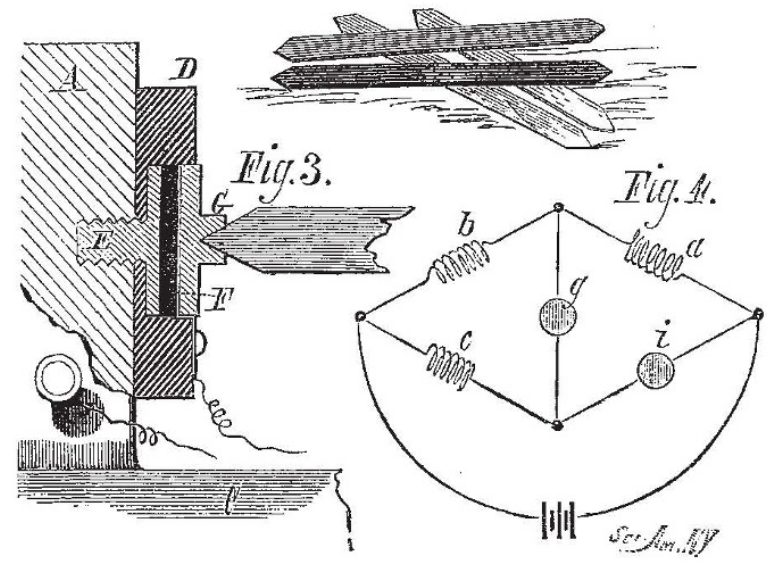

diminution of the pressure on the carbon button by an infinitesimal expansion or contraction of the substance under test is indicated on the scale of the galvanometer.

The carbon button may be compared to a valve, for when it is compressed in the slightest degree its electrical conductivity is increased, and when it is allowed to expand it partly loses its conducting power.

The heat from the hand held six or eight inches from a strip of vulcanite placed in the instrument-when arranged as last described-is sufficient to deflect the galvanometer mirror so as to throw the light-beam completely off the scale. A cold body placed near the vulcanite strip will carry the light-beam in the opposite direction.

Pressure that is inappreciable and undiscoverable by other means is distinctly indicated by this instrument.

Mr. Edison proposes to make application of the principle of this instrument to numberless purposes, among which are delicate thermometers, barometers, and hygrometers. He expects to indicate the heat of the stars and to weigh the light of the sun.

\section{KEW GARDENS REPORT}

SIR JOSEPH HOOKER'S Annual Report for 1877 is more than usually bulky, extending to fifty-three pages. The report opens with the number of visitors admitted to the gardens during the year, which amounted to 687,972 , a great excess over those of the preceding year. The points of public interest first treated of by the Director are, as might have been supposed, those affecting the agitation to remove the boundary wall along the Richmond Road and to open the gardens at an earlier hour. These points have been so freely discussed of late in the public press that we need do no more than refer to them. Referring to his visit to North America, Sir Joseph pays a high tribute to the intelligence and courtesy of the people. He says: "I cannot adequately express my sense of the liberality with which travelling facilities and hospitalities of all kinds were accorded to me by public companies and private individuals wherever I went in America. The fact of my being connected with this establishment [Kew] was a recognised passport, and this even in the remote settlements of the Far West, for I found a reading people everywhere, few of whom had not heard of Kew Gardens. In the Northern States of America the progress of science, and of institutions for the instruction of the people in science, occupy a prominent place in the cheap illustrated periodical literature of the masses; and nowhere on the globe is this literature better or so universally read as in the States. It is hence not wonderful that the progress of such establishments as Kew, the British Museum, South Kensington Museum, \&c., should be better known amongst all classes of the people there than they are in the United Kingdom generally, and so I found it."

Under the head of "Interchange of Plants and Seeds," as also under that of "Official Correspondence," a vast deal of information is gathered together on the acclimatisation, extended cultivation, or further development of useful plants. Thus we find the ipecacuanha (Cephaellis ipecacuanha), a native of Brazil, has been distributed from the Calcutta Botanic Garden to Ceylon, Singapore, Burmah, and the Andamans. Dr. King, however, does not take a very hopeful view of its ultimate success in India, partly on account of its peculiarly slow growth, which tends to prevent its cultivation being taken up with spirit by European planters, and partly on account of its insignificant appearance, which does not even excite interest. among the planters. Sir Joseph suggests it as "worthy of consideration whether the Indian government would not do well to establish a nursery in some part of our Indian possessions, with the tropical climatic conditions necessary for its growth." In connection with this subject, considering the great value of the ipecacuanha in cases of dysentery, it is satisfactory to note that there seems some prospect of its cultivation being attempted in the native states of Perak, where the soil and climate are considered to be well adapted to its requirements. Regarding the prophylactic virtues of Eucalyptus globulus - a subject which has been to some extent ventilated in our own columns-the experiences of the Kew authorities do not throw any further light on it. As valuable timber-trees, however, there can be no doubt that many of the species of Eucalyptus will prove most valuable. Sir Joseph says:-"The merits of the numerous species of 
this genus are beginning to be understood, and there is no doubt that, where the climate is suitable, few timber-trees can compare with them for rapidity of growth and excellence of wood. Popular misconceptions still, however, prevail on the subject, to some extent. Attempts to grow in tropical climates the species of temperate ones such as Eucalyptus globulus can only result in disappointment."

Two points of interest are recorded in connection with the botanical origin of Shiraz and Havana tobaccos. Hitherto the former has been stated, even upon the best authorities, to have been furnished by Nicotiana persica. It has, however, been proved from plants raised at Kew from seed of the finest Shiraz tobacco procured from Persia, to be merely a form of Nicotiana tabacum, the plant so largely cultivated in North America, and from which the bulk of the commercial tobacco is procured. To the same plant $N$. tabacum, var. macrophyllum, is attributed the Cuba and Havana kinds, which have always been described as the produce of $N$. repanda, no such species, so far as Dr. Vidal, the director of the Botanical Gardens, Manila, is aware, being found now in Cuba, either wild or cultivated.

An interesting subject is that connected with vegetable poisons, more particularly the arrow poisons. It is, as is stated, a subject "well deserving of investigation, although it has been doubted whether the ingredients employed have any really poisonous qualities." The evidence on these points is conflicting. Some of the plants from which these poisons are obtained have been promised to. Kew, so that before long we shall no doubt know something more definite about them.

Altogether the Kew report is, this year, one worthy not only of perusal, but to be retained for future reference.

\section{NOTES}

Writhin a short period Vienua has lost two of her leading scientific celebrities, von Littrow and von Ettingshausen. We regret to add to the list the name of Baron Karl von Rokitansliy, the President of the Viema Academy of Sciences, who died on Iuly 23 at the age of seventy-four. He was born at Königgrätz, in Bohemia, February 19, 1804. After completing his medical studies at the Universities of Prague and Vienna, he became, in 1828, assistant in the Pathological Anatomical Institute at Vienna. In 1834 he accepted the chair of pathological anatomy in the University, fulfilling, in addition, the duties of prosector in the Vienna hospital, and of legal anatomist for the city. In these varied functions an enormous mass of observations was accumulated, which served as a basis for his "Lehrbuch der pathologischen Anatomie," which appeared in five volumes, I $842-1846$, and has survived three editions. At this period von Rokitansky commenced a remarkable series of investigations with the microscope, which Johannes Müller, a few years prewiously, had introduced into physiological research. From the results of these and other lines of investigation, he rapidly won for pathological anatomy an importance which had been hitherto wanting in German schools of medicine, and caused its recognition as the foumdation for all research, not only in pathological physiology, but in the whole province of medicine. The old symptomatic system of classification was replaced by a careful discrianinating study of the changes brought about in individual organs by the varied forms of disease. The delicate appliances of modern science enabled him to detect a large number of new Giseases, which had hitherto been classed with other diseases on account of the apparent similarity in symptoms. To the classical researches of von Rolitansky, probably more than to any other source, modern diagnosis owes its ferfection. The impulse given by him was ably seconded by the contemporary medical aathorities of Austria, and on the basis of the principles formu. lated by von Rokitansky, Hebra in dermatology, Engel in general anatomy, Oppolzer in therapeutics, and Dittrich, Schuh, and Skcda in other special departments of medicine have grounded the famous so-called Viemna-Prague school. Von Rokitansky retired from his professorship three years ago, and published at the same time his last work, "Die Defekte der Scheidewäncle des Herzens." His merits won for him numerous marks of distinction, and for some time past he has presided over the Imperial Academy of Sciences. He leaves behind him a son, Professor of Music at the Vienna Conservatorium.

WE have received, from the Ethnological Museum of Leipzig, a circular, signed by Drs. Magnus and Pechuël-Loesche, of great importance in reference to the much-debated question as to the development of the sense of colour in men. The object of this circular is to obtain data as to what degree uncivilised peoples perceive colours and distinguish them by names, after the manner of civilised nations. The circular contains a series of inquiries in German and English, along with a scale of colours, and a schedule in which to record the replies to the various questions. The instructions are carefully drawn up, and. Drs. Magnus and Loesche intend to distribute the circular by thousands; if the instructions are strictly adhered to the result must be of great value. We believe this circtiar is only the first of a long series which Dr. Pechuël-Loesche is preparing with the intention of enlarging, in a systematic way, our ethnological knowledge, and especially to solve interesting psychological problems regarding uncivilised tribes. The Ethnological Museum of Leipzig has agreed to receive and take care of all the material collected, which will be at the command of any scientific in quirers who may care to make use of it. We need say nothing in support of this enterprise of Drs. Magnus and Loesche; we wonld simply urge upon all our readers who are in a position to lend a helping hand, either directly or through friends living abroad, to obtain a supply of the circular referred to, by apply. ing to Dr. Pechuël-Lsesche, Museum für Völkerkunde, Leipzig, Germany.

IN the year I85I the Viema Academy of Sciences offered a prize for determination of the "Crystalline forms of products obtained in chemical laboratories," which proved fruitful, to a remarliable extent, in crystallographic researches of much im. portance. More recently new problems have come up with reference to crystallisation, partly in consequence of the labours just referred to, and partly because of the new discoveries of chemistry with regard to the structure of chemical molecules. Wishing to promote research in this direction, the Academy offer a prize of $\mathrm{I}, 000 \mathrm{fl}$. for "Investigation of the crystalline form of chemical substances, with special reference to homologous series and isomeric groups. A determination of the specific gravity is also desired. The carrying out of optical researches on the crystals measured is deferred for measurement by the winner of the prize." The limit of time is December 3I, 1879, and the prize will be awarded in 1880 . Papers to be sent in with sealed envelopes and mottoes.

Prof. TAIT is, we hear, engaged in developing for fog signalling purposes a form of apparatus producing intense sounds with great economy of driving power, which he some time ago exhibited at the Royal Society of Edinburgl. His mechanism is, we believe, devised to produce an effect analogous to that of the drum, which is one of the most economic of noise-producing instruments.

THE commission appointed by the French Government to test the rope used by $M$. Giffard in the construction of his captive balloon have made their experiments. We have already said that the rope is conical, the heaviest end being uppermost, so that, if any breakage should take place, it will not be in the vicinity of the car, but close to the 